\title{
A differential capacity of arbuscular mycorrhizal fungal colonization under well-watered conditions and its relationship with drought stress mitigation in unimproved vs improved soybean genotypes
}

\begin{tabular}{|r|l|}
\hline Journal: & Botany \\
\hline Manuscript ID & cjb-2017-0137.R1 \\
\hline Manuscript Type: & Article \\
\hline Date Submitted by the Author: & 17-Oct-2017 \\
\hline $\begin{array}{r}\text { Complete List of Authors: } \\
\text { Is the invited manuscript for } \\
\text { consideration in Special } \\
\text { Issue? : }\end{array}$ & $\begin{array}{l}\text { Salloum, Maria; Instituto Nacional de Tecnologia Agropecuaria, Cordoba } \\
\text { Luna, Celina; Instituto Nacional de Tecnologia Agropecuaria, Cordoba }\end{array}$ \\
\hline Keyword: & $\begin{array}{l}\text { Arbuscular mycorrhizal fungi (AMF), drought tolerance, oxidative stress, } \\
\text { improved and unimproved soybean, mycorrhizal dependency }\end{array}$ \\
\hline &
\end{tabular}


1 A differential capacity of arbuscular mycorrhizal fungal colonization under well-watered conditions and

2 its relationship with drought stress mitigation in unimproved vs improved soybean genotypes

3 María Soraya Salloum ${ }^{\mathrm{a}^{*}}$, María Florencia Menduni ${ }^{\mathrm{b}^{*}}$, Celina Mercedes Luna ${ }^{\mathrm{a}^{* *}}$

4

5 (a) Consejo Nacional de Investigaciones Científicas y Técnicas (CONICET)-Instituto Nacional de 6 Tecnología Agropecuaria (INTA), Centro de Investigaciones Agropecuarias (CIAP), Instituto de 7 Fisiología y Recursos Genéticos Vegetales (IFRGV). Camino 60 cuadras, Km 5,5 C.P. 5119, Córdoba, 8 Argentina.

9 (b) Fondo para la Investigación Científica y Tecnológica (FONCyT) - Instituto Nacional de Tecnología 10 Agropecuaria (INTA), Centro de Investigaciones Agropecuarias (CIAP), Instituto de Fisiología y 11 Recursos Genéticos Vegetales (IFRGV). Camino 60 cuadras, Km 5,5 C.P. 5119, Córdoba, Argentina.

\section{$12 * *$ Corresponding author}

13 e-mail: luna.celina@inta.gob.ar

14 Telephone: 0054-0351-4973636

15 Fax: 0054-0351-4974330

Abstract

Modern breeding programs may cause a reductionin plant responsiveness to arbuscular mycorrhizal (AM) fungi. In this study, we tested the hypothesis that a higher arbuscule formation and mycorrhizal dependency (MD) response in unimproved soybean genotypes than improved is related to drought stress tolerance caused by enhanced growth parameters andoxidative stress regulation. Firstly, 4 unimproved and 4 improved soybean genotypes were compared under well-watered conditions. After 20 days, all unimproved soybean genotypes showed a higher increase in arbuscule formation, as well as a positive and higher MD index in foliar mineral nutrient and growth parameters than 4 improved. Secondly, tolerance to drought stress was evaluated in two improved soybean genotypes and two unimproved, selected for the most contrasting response to arbuscule formation, under well-watered conditions. After 20 days of $30 \%$ of field capacity, arbuscule formation was higher in unimproved than improved genotypes. Mycorrhizal dependency evaluated as leaf area, shoot and root dry mass were highest in AM unimproved genotypes. Moreover, malondiadehide was lower and proline was higher in unimproved than improved genotypes. The potential capacity of arbuscule formation is discussed as a selection criterion to identify improved soybean genotypes with increased efficiency under well-watered conditions and an enhanced capacity to relieve drought stress. 
33 Keywords: Arbuscular mycorrhizal fungi (AMF); drought tolerance; oxidative stress; improved and 34 unimproved soybean; mycorrhizal dependency.

35

$36 *$ Authors contributed equally in this paper.

\section{Introduction}

Many investigations have demonstrated that arbuscular mycorrhizal (AM) fungi enhance not only growth and mineral element uptake, but also resistance to drought stress (Ruiz-Lozano et al. 1995; Augé 2001; Rapparini and Peñuelas 2014; Saia et al. 2014; Grumberg et al. 2015). However, modern breeding programs might have caused a reduction in plant responsiveness to AM fungi (Peréz-Jaramillo et al. 2016). The effect of domestication and plant breeding was addressed by pioneering studies evaluating the ability of ancestors, landraces and modern wheat genotypes to sustain AM symbiosis (Kapulnik and Kushnir 1991). Differences in mycorrhizal dependency (MD), defined by Plenchette et al. (1983) as the degree of plant growth change associated with AM colonization, were higher in modern $T$. aestivum cultivars and ancestors released before 1950 than in those released later (Hetrick et al. 1992; 1995). Zhu et al. (2001) also found a reduction in mycorrhizal responsiveness in Australian modern wheat cultivars as compared to old cultivars. Tawaraya (2003) reported that cultivated plant species showed a lower MD than wild ones. In these studies, the highly fertile conditions used during the plant breeding process were proposed as a possible explanation for the reduced mycorrhizal dependence of modern genotypes. By contrast, Bryla and Koide (1990) and Allen (1991) reported that wild type plants were found to be less dependent on mycorrhiza. Furthermore, in maize plants, An et al. (2010) found that modern hybrids showed significantly greater values than inbred lines and older landraces. In a metagenomic analysis, Lehmann et al. (2012) did not find evidence that new crop plant genotypes had lost their ability to respond to mycorrhiza due to agricultural and breeding practices. They observed that although new cultivars were less intensely colonized, they were more mycorrhiza-responsive (and possibly dependent) than ancestral genotypes.

Particularly in soybean, Heckman and Angle (1987) reported variability in root colonization by indigenous soil populations of AM fungi. Khalil et al. (1994; 1999) found that both AM fungal colonization and MD increased in unimproved soybean genotypes, showing greater benefits from mycorrhizal symbiosis than improved cultivars. Accordingly, Khalil et al. (1994) suggested that unimproved soybeans, such as Glycine soja, may be an important source of breeding material for optimizing AM associations. Recently, our group showed differences in AM colonization between improved and unimproved soybean genotypes (Salloum et al. 2016), with AM unimproved soybean genotypes showing a higher arbuscule formation and a faster MD response evaluated as growth

67 parameters and oxidative stress regulation under well-watered conditions. However, differences between

68 AM colonization and tolerance to drought stress between improved and unimproved soybean genotypes 69 have still not been assessed. 
Soybean growth, development and yield are greatly affected by several abiotic stressors, such as drought (Mohammadi et al. 2012). In Argentina, soybean production has been extended to less fertile and arid areas than traditionally used (Pérez Brandán et al. 2012); therefore, the objectives of this study were: firstly, to validate previous results (Salloum et al. 2016) by contributing with information about AMimproved vs AM-unimproved soybean genotypes under well-watered conditions and secondly, to assess AM colonization and tolerance to drought stress of improved vs unimproved soybean genotypes by measuring growth and biochemical parameters related to oxidative stress: chlorophyll; malondialdehide; total antioxidant capacity measured as the ferric-reducing antioxidant power, assay (FRAP) content; and osmotic potential regulation, measured as proline foliar content (Gill and Tuteja 2010). We postulate that a higher arbuscule formation and MD response in unimproved soybean genotypes than in improved ones is related to drought stress tolerance, via enhanced oxidative stress and osmotic potential regulation. Since drought stress is one of the most important stressors in the world, we highlight the importance of selecting soybean genotypes with enhanced capacity for AMF colonization.

\section{Materials and methods}

Plant and fungal material

This study assessed four improved soybean (Glycine max) genotypes and four unimproved soybean (Glycine soja), genotypes. The improved genotypes included DM 50048 (I-1) and NA 5009 (I-2), characterized in Salloum et al. (2016), and INTACTA (I-3) and SYNGENTA $4 X 9$ (I-4). The unimproved genotypes included PI57440 (UI-3) and PI90768 (UI-4), characterized in Salloum et al. (2016), as well as PI89772 (UI-1) and PI 548510 (UI-2). All genotypes belong to Farming Experimental Station of the National Agricultural Technology Institute (EEA-INTA)-Marcos Juárez germplasm collection in Cordoba, Argentina. The mixed AMF inoculum was isolated from soybean roots collected from a soybean monoculture system developed in EEA INTA Manfredi-Argentina. The inoculum was isolated and multiplied in pots containing sterile sand/soil mix $(1: 1 \mathrm{v} / \mathrm{v})$, using soybean and Medicago sativa as plant-trap, under greenhouse conditions at $26{ }^{\circ} \mathrm{C}$, and watered daily with distilled water, for two years. The mixed AMF inoculum has been morpho-taxonomically described in Salloum et al. (2016). The mixed AMF inoculum was dominated by Funneliformis mosseae, with 427 spores per $100 \mathrm{~g}$ of dry soil, followed by Paraglomus occultum with 147 spores, Diversispora spurca with 112 spores, Glomus sp. with 22 spores, and Acaulospora scrobiculata and Gigaspora sp., with only 7 and 3 spores, respectively.

Plant-fungus bioassays

Seeds of soybean genotypes were sterilized using 18\% hypochlorite for 30 seconds. Then, pregerminated seeds were introduced in 1-kg pots containing a sterile sand/soil mix (1:1) substrate and watered daily with distilled water. The soil used in the experiment contained $4.8 \mathrm{ppm} \mathrm{N}-\mathrm{NO}_{3}, 2.5 \mathrm{ppm} \mathrm{S}$ $\mathrm{SO}_{4} ; 5.9 \mathrm{ppm} \mathrm{P,} \mathrm{3.09 \%} \mathrm{organic} \mathrm{matter,} 1.79 \%$ organic carbon, $0.162 \%$ total nitrogen, $11.1 \mathrm{C} / \mathrm{N}$ ratio, and $\mathrm{pH}$ of 6.7 (as determined in Soil laboratory in the University of Agronomy-Córdoba-Argentina). The mycorrhizal inoculum consisted of $20 \mathrm{~g}$ of soybean root fragments, spores and mycelia. Treated plants (hereafter referred to as AM plants) were inoculated in the center of the pot; non-AM plant treatments received the same amount of autoclaved inoculum. Before autoclaving, the inoculum was filtered with 
109

110

111

112

113

114

115

116

117

118

119

120

121

122

123

124

125

126

127

128

129

130

131

132

133

134

135

136

137

138

139

140

141

142

143

144

145

146

147

148

deionized water through a $37-\mu \mathrm{m}$ sieve (Schleicher \& Schuell, Germany). The filtrate was added to the non-AM planting pots to provide them with the microbial populations accompanying the AM fungi, following Porcel and Ruiz Lozano (2004). The AMF structures in the roots were stained according to Phillips and Hayman (1970) and we identify as hyphae each of the branching filaments that make up the mycelium of fungus; coiled hyphae as intracellular curls of hyphae (coils) and arbuscules as intricately branched haustoria formed within a root cortex cells (Smith and Read 2008). Mycorrhizal colonization was measured following McGonigle et al. (1990).

Experimental system under well-watered conditions

The experiment was conducted in greenhouse under controlled light conditions with a photoperiod of $8 \mathrm{~h}$ of darkness and $16 \mathrm{~h}$ of light and temperature $26^{\circ} \mathrm{C}$. An $8 \times 2 \times 1$ factorial randomized block design included the eight study cultivars; two inoculation treatments: a non-arbuscular mycorrhizal treatment and a treatment with mixed AM fungi inocula (non-AM and AM, respectively), and one moisture regime: well-watered conditions for 20 days. Thus, there were 16 treatment combinations replicated 10 times in three trials. The soil in the pots was watered with distilled water twice a week to maintain soil water content at field capacity. Plant biomass and mineral nutrient content were evaluated after the 20-day watering period. Mineral nutrient content in extract from leaves was determined by chromatography with conductivity detection, according to Cataldi et al. (2003).

Experimental system under drought stress conditions

The experiment was conducted in a growth cabinet set at $26^{\circ} \mathrm{C}, 8 \mathrm{~h}$ of darkness and $16 \mathrm{~h}$ of light. The average photosynthetically active radiation (PAR) in the cabinet was approximately $350-400 \mu \mathrm{mol}$ $\mathrm{m}^{-2} \mathrm{~s}^{-1}$. The drought stress test was performed using a $4 \times 2 \times 2$ factorial randomized block design that included four cultivars (I-1, I-2, UI-3 and UI-4); two inoculation treatments: a non-arbuscular mycorrhizal treatment and a treatment with mixed AM fungi inocula (non-AM and AM, respectively); two moisture regimes: well-watered and drought-stressed conditions. Thus, there were 16 treatment combinations replicated 10 times in three trials. The two improved (I-1 and 2) and two unimproved (UI-3 and 4) soybean genotypes; were selected because they exhibited contrasting response to AM colonization, particularly arbuscule formation under well-watered conditions in this study and in Salloum et al. (2016).

Water soil field capacity (FC) was determined according to the following formula: Water soil FC $(\%)=100 \mathrm{X}(\mathrm{MSW}-\mathrm{DSW}) / \mathrm{DSW}$, where DSW stood for dry soil weight, MSW for moisture soil weight at FC. The soil of all pots was dried in an oven at $105{ }^{\circ} \mathrm{C}$ for 48 hours, determining the DSW of each pot. Then, in order to determine MSW, they were watered at saturation and the weight of each pot was taken when the drainage stopped. According to the formula, the soil water content at FC was $25 \%$. The soil of all pots was irrigated with distilled water twice a week to maintain soil water content at FC during the first 20 days of plant growth. Then the soil in half of the potswas allowed to dry to $30 \% \mathrm{FC}$ (where the water content in the soil was 7.5\%), while the other half was maintained at FC. The soil moisture was maintained daily by weighing the pots and replenishing the amount of water lost.

Determination of plant growth and oxidative stress parameters

https://mc06.manuscriptcentral.com/botany-pubs 
Plant biomass was measured as root and shoot fragments, after drying to a constant weight of 70 ${ }^{\circ} \mathrm{C}$. Leaf area was estimated from the first trifoliate leaves by tracing the leaflet outlines on paper, cutting out the paper and weighing the cutouts; those weights were compared with the weight of a known area of paper $\left(1 \mathrm{~cm}^{2}\right)$. Biochemical characters of oxidative stress were evaluated using $100 \mathrm{mg}$ frozen tissue of the second trifoliate soybean leaves. Oxidative damage was measured as lipid peroxidation, estimated as the content of 2-thiobarbituric acid-reactive substances and expressed as equivalents of malondialdehyde, according to Hodges et al. (1999). Total chlorophyll was estimated by extracting the leaf material in $80 \%$ ethanol after incubation at $80^{\circ} \mathrm{C}$ for $15 \mathrm{~min}$. Absorbance was recorded at 665,645 and $470 \mathrm{~nm}$ and total chlorophyll was calculated according to Arnon (1949). Total antioxidant capacity was evaluated as FRAP (Benzie and Strain 1996). This method measures the ability of antioxidants to reduce ferric iron. It is based on the reduction of the complex of ferric iron and 2,3,5-triphenyl-1,3,4-triaza-2-azoniacyclopenta1,4-diene chloride (TPTZ) to the ferrous form at low $\mathrm{pH}$. This reduction is monitored by measuring the change in absorption at $593 \mathrm{~nm}$. Proline concentration was determined by the modified method of Bates et al. (1973).

\section{Statistical analysis}

Plant biomass (leaf area, shoot and root dry mass) and oxidative stress parameters (malondialdehide; FRAP, chlorophyll and proline) were expressed as MD index, following Janos (2007), which was calculated as [(AM-non-AM)/AM] x 100, using individual values of AM plants, and mean values of non-AM plants. Each treatment included 10 replicates and three repetitions. Data obtained from three repetitions were pooled. The results were analyzed by analysis of variance (ANOVA). Probabilities of significance were used to test for significance among treatments and interactions, and differences among means were compared using Fischer's F test $(p \leq 0.05)$. Data analyses were performed with the statistical package INFOSTAT (Di Rienzo et al. 2013). No data transformation was required because MD percentage in morphological traits and biochemical parameters was normally distributed.

\section{Results}

Arbuscular mycorrhizal fungus colonization under well-watered conditions: differences between improved and unimproved soybean genotypes

After 20 days of treatment under well-watered conditions, the highest percentages in total mycorrhization, particularly arbuscule formation, were observed in unimproved soybean genotypes (Table 1). Thus, UI-1, UI-2 and UI-4 had the highest content of arbuscules followed by UI-3 and I-2, with the same the same percentage of arbuscules (Table 1). Moreover, all unimproved soybean genotypes showed a similar percentage of total mycorrhizal colonization and arbuscule formation, whereas improved ones showed more variability. Thus, AM colonization of I-1, particularly arbuscule percentage, was the lowest among improved genotypes. Hypha and vesicle percentage varied among treatments and in general, improved genotypes showed a higher percentage in vesicles than unimproved ones. Mycorrhizal colonization was not observed in roots of non-AMF seedlings exposed to well-watered conditions. All AM soybean lateral roots were larger and denser than non-AM soybean roots. In addition, 
no differences in root morphology were observed between improved and unimproved soybean genotypes (see Fig. S1 in supplementary material).

Growth biomass and foliar mineral nutrient content under well-watered conditions: differences between mycorrhizal improved and unimproved soybean genotypes

After 20 days of exposure to well-watered conditions, biomass growth of both unimproved and improved soybean genotypes was increased by AM inoculation, as indicated by a positive MD index in leaf area, and in shoot and root dry mass (Fig. 1). However, MD index was higher in AM unimproved soybean genotypes than in improved ones. In addition, foliar $\mathrm{PO}_{4}, \mathrm{NO}_{3}$ and $\mathrm{S}_{4}$ content showed a positive MD index in both unimproved and improved soybean genotypes (Fig. 2), with MD index being higher in all unimproved soybean genotypes than in improved ones. Moreover, while none of the unimproved soybean genotypes showed variability in MD level related to growth biomass and foliar mineral nutrient content, improved ones were variable, with I-1 showing the lowest MD response (Fig. 1 and 2).

\section{Arbuscular mycorrhizal fungus colonization under drought stress: differences between improved and unimproved soybean genotypes}

In general, after 20 days of drought stress a significant decrease in total percentage of AM colonization was recorded with respect to AM soybean control plants. Under both control and droughtstressed treatments, no differences were observed in the percentage of hyphae and coiled hypahe structures between unimproved and improved soybean genotypes. However, total percentage of AM colonization, particularly arbuscule formation, was higher in both unimproved genotypes under control and drought-stressed conditions than in improved ones (Table 2). Particularly, variability in arbuscule formation among improved genotypes was observed under drought-stress, with I-1 showing a lower percentage than I-2 soybean genotype. Moreover, under drought- stress, AM soybean lateral roots were larger and denser than non-AM soybean roots (see Fig. S2 in supplementary material). In addition, this effect was more evident in root morphology of unimproved soybean genotypes. No mycorrhizal colonization was observed in roots of non-AMF seedlings, regardless of irrigation conditions.

\section{Growth biomass, oxidative stress and proline regulation under drought stress: differences between} mycorrhizal improved and unimproved soybean genotypes

Under control conditions (40 days after sowing), MD evaluated as shoot dry mass and leaf area, was positive in both unimproved and I-2, while I-1 showed a variable response in leaf area. Moreover, under drought-stress, I-1 was strongly affected, as indicated by a negative shoot dry mass, whereas both unimproved genotypes as well as I-2 soybean genotype showed a higher and positive MD index (Fig. 3). Forty days after sowing, chlorophyll content showed a positive MD index in control plants, which was related to AM treatments, being highest in I-1. By contrast, after 20 days of drought-stress, chlorophyll content decreased in all treatments (Fig. 4). Particularly, this behavior was marked in I-1 soybean genotype, which showed a negative MD index. 
Oxidative damage level, evaluated as malondialdehide content, showed a reduction in AM

225

226

227

228

229

230

231

232

233

234

235

236

237

238

239

240

241

242

243

244

245

246

247

248

249

250

251

252

253

254

255

256

257

258

259

260

261 treatments, under control and drought-stressed conditions, as indicated by a negative MD index. Under control conditions, the highest negative MD index was observed in I-1. By contrast, under drought-stress, I-1 showed a significant change in MD index, with an increase in oxidative damage level as suggested by a less negative MD index (Fig. 5). After 20 days of drought-stress and compared to control soybean plants, no changes in MD index were evident either in unimproved genotype or in I-2 soybean plants. Mycorrhizal dependency evaluated as FRAP content was positive under control conditions, with I-1 showing the highest value. Under drought-stress, both unimproved genotypes and I-2 and, to a lesser extent, I-1, showed a negative MD index (Fig. 6). Under well-watered conditions, both unimproved genotypes followed by I-2 showed a positive MD index, measured as proline content, whereas I-1 exhibited a negative response. Proline content was positive after drought-stress, with significant and higher MD index in both unimproved genotypes followed by I-2 and a lesser extent by I-1, as compared with MD in control soybean plants, (Fig. 7).

\section{Discussion}

Domestication is a complex evolutionary process involving morphological and physiological changes that lead to the differentiation of domesticated taxa from their wild ancestors (Hancock 2005). Domestication of plant species has been related to a decrease in the genetic diversity of modern crop cultivars, which may have affected the ability of plants to establish beneficial associations with rhizosphere microbes (Peréz-Jaramillo et al. 2016). Some investigations in soybean (Khalil et al. 1994; 1999) found that increase in both AM fungal colonization and MD were higher in unimproved soybean genotypes than in modern cultivars, with variability between improved soybean ones (Salloum et al. 2016) under well-watered conditions. Our study makes a novel contribution by analyzing AM improved vs unimproved soybean genotypes in their tolerance to drought-stress.

In this study, under well-watered conditions, different unimproved soybean genotypes showed a higher total AM colonization than improved ones, supporting previous observations of Salloum et al. (2016). These results are also in agreement with findings of Khalil et al. (1994), who reported percentages of unimproved and improved soybean roots colonized by AMF ranging from $62 \%$ to $87 \%$, with the highest colonization being detected in Glycine soja (average 84\%). Interestingly, in our study, all unimproved soybean genotypes exhibited a higher arbuscule formation than improved ones. A similar result was reported by Salloum et al. (2016). In Breadfruit (Artocarpus sp.), Xing et al. (2012) showed that both vesicular and arbuscular colonization rates decreased significantly in more recently derived breadfruit cultivars. The differential capacity of arbuscular formation between unimproved and improved soybean genotypes was coincident with a differential MD index. Thus, the positive MD index expressed as biomass growth and mineral nutrient content was higher in unimproved than in improved soybean genotypes. Similarly, Khalil et al. (1994) reported that MD, measured as biomass parameters in soybean genotypes, ranged from 40 to $94 \%$, with Glycine soja having the highest MD. Moreover, our results related to mineral nutrient content are in agreement with those of Khalil et al. (1999), who observed that 
262 AM-Glycine soja had 7.8 times greater total shoot P than non-AM-Glycine soja, whereas comparable

263

264

265

266

267

268

269

270

271

272

273

274

275

276

277

278

279

280

281

282

283

284

285

286

287

288

289

290

291

292

293

294

295

296

297

298

299

300

301

values were 2.4 for Mandarin and 1.5 for Swift, the improved soybean ones. They also observed that Glycine soja roots showed higher phosphatase activity with mycorrhizal colonization than the other two cultivars. Moreover, Zhu et al. (2001) reported a lower mycorrhizal responsiveness, measured as shoot $\mathrm{P}$ concentration, in modern wheat cultivars than in old cultivars. On the other hand, differences in root architecture between modern cultivars and their wild relatives have been described for a number of crops. For instance, a shallower root system was developed in cultivated lettuce, Lactuca sativa, than in wild Lactuca serriola (Jackson 1995). In our study under both well-watered and drought-stressed conditions, AM lateral roots were larger and denser than non-AM soybean roots, suggesting an enhanced capacity for mineral nutrient uptake in AM soybean plants. However, no changes in AM mycorrhizal root morphology were evident between AM improved and unimproved soybean genotypes, under well-watered, suggesting that breeding selection did not affect root morphology in mycorrhizal soybean plants under these conditions. In contrast, differences in root morphology were observed between AM improved and unimproved soybean genotypes under drought-stressed conditions, at least at an early stage of colonization. Further studies, including more soybean genotypes and quantitative analyses of roots, should be conducted to test genetic variation in AM and non-AM unimproved vs improved soybean genotypes.

Drought-stress reduced AMF percentage colonization in all AM soybean treatments. These results support previous findings showing that mycorrhizal colonization would be reduced under a low soil moisture level (Shukla et al. 2013; Wu et al. 2017). This effect of drought-stress on AMF colonization has been related to a decrease of the overall metabolic rate caused by water deficiency (Dell'Amico et al. 2002) or inhibition of spore germination and the spread of hyphae in soils (Wu et al. 2017). Although the depressive effect of drought-stress on mycorrhizal colonization was similar in both improved and unimproved soybean genotypes, the levels of total mycorrhizal percentage and arbuscule formation were highest in both unimproved genotypes. To our knowledge, our study is the first report of variability in arbuscule formation between unimproved and improved soybean genotypes under droughtstressed conditions, suggesting that breeding selection was able to modify arbuscule formation capacity in soybean plants, not only under well-watered conditions but also under drought-stress. Arbuscules appear as the most important structure of AM fungi, because they may facilitate bidirectional exchange of nutrients between plants and the fungus (Smith and Smith 2011). Recently, Park et al. (2015) demonstrated that arbuscule branching is related to different levels of arbuscular colonization and productive symbiosis.

Many investigations showed that AM fungi are important in sustainable agriculture because they improve plant water relations and thus increase the drought resistance of host plants (Gianinazi et al. 2010; Aroca et al. 2012). In our study, under drought-stress, MD index, evaluated as biomass growth and chlorophyll content, was positive and higher in both unimproved genotypes, followed by I-2 and a lesser extent I-1. A similar behaviour was observed when absolute data of growth parameters and chlorophyll content were compared between AM and non AM-unimproved and improved soybean genotypes, under drought-stress (Supplementary Table S1 and S2), suggesting that breeding selection reduced droughtstress tolerance of AM soybean plants.

https://mc06.manuscriptcentral.com/botany-pubs 

stress has been considered a crucial mechanism by which AM symbiosis increases salinity and drought resistance of host plants (Ruiz-Lozano 2003; Borde et al. 2011; Rapparini and Peñuelas 2014; Nath et al. 2016). In this study, our results showed variability in oxidative stress response between AM unimproved and improved soybean genotypes, subjected to drought-stress.

Thus, MD index measured as malondialdhide level, a marker of oxidative damage in AMFplants (Porcel and Ruiz Lozano 2004; Zhu et al. 2011; Zhang et al. 2010; Grumberg et al. 2015), was more negative in unimproved soybean plants, suggesting better antioxidant capacity in those genotypes than in improved ones. However, in our study, after drought-stress, MD index as FRAP was negative and it was lower in both unimproved genotypes and I-2, and a lesser extent I-1. Total antioxidant capacity as FRAP assay, is determined by a large variety of antioxidant molecules, including polyphenols, tocopherols, glutathione and ascorbic and its increase, has been related to enhanced antioxidant defense in AMF plants (Jugran et al. 2015). But also, Marulanda et al. (2007), reported low accumulations of both glutathione and ascorbate in mycorrhizal plants of lavender under drought conditions, suggesting that these antioxidant compounds can be viewed as markers of drought-stress, correlated with a high level of tolerance to plant drought. Furthermore, enhanced accumulation of proline has been linked to AMinduced drought tolerance, with proline acting as osmoprotectant or an effective scavenger of reactive oxygen species (Porcel and Ruiz Lozano 2004; Rapparini and Peñuelas 2014). In our study under drought-stress, we observed a higher MD measured as proline content in unimproved soybean genotypes than in improved ones, suggesting a better osmotic potential regulation in unimproved than improved soybean ones, although we can't rule out, proline and their antioxidants effects. In that sense, in grape leaves of Vitis vinifera $\mathrm{L}$. exposed to oxidative stress by $\mathrm{H}_{2} \mathrm{O}_{2}$, the presence of proline modified key antioxidant enzymes activities. Also, proline pre-treatment resulted in a decrease in cellular $\mathrm{H}_{2} \mathrm{O}_{2}$ content, malondialdehide and electrolyte leakage, while cellular concentration of proline increased (Ozden et al. 2009). Overall, both MD index and absolute data (see Supplementary Table S1 and S2) of chlorophyll, malondialdehide, FRAP and proline content showed variability between AM unimproved and improved soybean genotypes subjected to drought-stress, suggesting that domestication in AM soybean plants promoted variability in oxidative stress tolerance under drought-stress conditions.

In summary, unimproved soybean genotypes exhibited a higher capacity for arbuscular formation than improved ones; and it was consistent with an increase in drought-stresstolerance, as suggested by a higher biomass with a lower oxidative damage. By contrast, both improved soybean genotypes showed variability in MD index. Thus, and in agreement with Salloum et al. (2016), I-1 genotype showed an increase in MD index with time under well-watered conditions. However it exhibited a lower MD under drought-stress, than I-2, supporting the idea that the selection of soybean genotypes based on their MD could be misleading, as suggested by Singh et al. (2012) in improved wheat genotypes. In that sense, we are currently conducting studies that include a higher number of improved genotypes to test genetic variation in soybean genotypes, and particularly, we will analyze, the capacity for arbuscule formation, as a selection criterion for improved soybean genotypes with enhanced drought- 
342

343

344

345

346

347

348

349

350

351

352

353

354

355

356

357

358

359

360

361

362

363

364

365

366

367

368

369

370

371

372

373

374

375

376

377

378

379

\section{Acknowledgements}

This work was funded by National Promotion Agency Science and Technology (ANPCyT) through the Fund for Scientific Research and Technology (FONCyT): Projects of Scientific and Technological Research (PICT) 2012-0339 and by the National Institute of Agricultural Technology (INTA) through Projects $\mathrm{N}^{\circ} 1133032$ and $\mathrm{N}^{\circ} 1127033$. The National Council of Scientific and Technical Research (CONICET) awarded the scholarship to M.S. Salloum and Scientific Research and Technology (FONCyT) awarded the scholarship to F. Menduni. We are very grateful to Dr J. Gilli for providing the soybean seeds. The authors are thankful to J. Ruarte for technical assistance and J. Brasca for manuscript language editing.

\section{References}

Allen, M.F. 1991. The ecology of mycorrhizae. Cambridge University Press.

An, G.H., Kobayashi, S., Enoki, H., Sonobe, K., Muraki, M., Karasawa, T., and Ezawa, T. 2010. How does arbuscular mycorrhizal colonization vary with host plant genotype? An example based on maize (Zea mays) germplasms. Plant and Soil, 327:441-453.

Arnon, D.I. 1949. Copper enzymes in isolated chloroplasts. Polyphenol oxidase in Beta vulgaris. Plant Physiol. 24: 1-15.

Aroca, R., Porcel, R., and Ruiz-Lozano, J.M. 2012. Regulation of root water uptake under abiotic stress conditions. J. Exp. Bot. 63: 43-57.

Ashraf, G. 2010. Anti-Oxidation Profile in the Leaves of Maize Inbreds: Elevation in the Activity of Phenylalanine Ammonia Lyase under Drought-stress. Journal of Plant Sciences, 5: 137-145.

Auge, R.M. 2001. Water relations, drought and VA mycorrhizal symbiosis. Mycorrhiza, 11: 342.

Bates, L.S., Waldren, R.P., and Teare, I.D. 1973. Rapid determination of free proline for waterstress studies. Plant soil, 39: 205-207.

Benzie, I.F., and Strain, J.J. 1996. The ferric reducing ability of plasma (FRAP) as a measure of "antioxidant power": the FRAP assay. Anal. Biochem. 239: 70-76.

Borde, M., Dudhane, M., and Jite, P. 2011. Growth photosynthetic activity and antioxidant responses of mycorrhizal and non-mycorrhizal bajra (Pennisetum glaucum) crop under salinity stress condition. Crop Protection, 30: 265-271.

Bryla, D.R., and R.T. Koide. 1990. Role of mycorrhizal infection in the growth and reproduction of wild vs. cultivated plants: 11. Eight wild accessions and two cultivars of Lycopersicon esculentllm Mili. Oecologia, 84:82-92.

Cataldi, T.R., Margiotta, G., and Del Fiore, A., and Bufo, S.A. 2003. Ionic content in plant extracts determined by ion chromatography with conductivity detection. Phytochem. Anal. 14: 176-183.

Dell'Amico, J.M., Rodríguez, P., Torrecillas, A., Morte, A., and Sánchez-Blanco, M.J. 2002. Influencia de la micorrización en el crecimiento y las relaciones hídricas de plantas de tomate sometidas a un ciclo de sequía y recuperación. Cultivos Tropicales, vol. 23. pp. 29-34. 
Di Rienzo, J.A., Casanoves, F., Balzarini, M.G., Gonzalez, L., Tablada, M., and Robledo, C.W. 2013. InfoStat versión 2013. Grupo InfoStat, FCA, Universidad Nacional de Córdoba, Argentina. URL http://www.infostat.com.ar.

Gianinazzi, S., Gollotte, A., Binet, M.N., van Tuinen, D., Redecker, D., and Wipf, D. 2010. Agroecology: the key role of arbuscular mycorrhizas in ecosystem services. Mycorrhiza, 20: 519-530.

Gill, S.S., and Tuteja, N. 2010. Reactive oxygen species and antioxidant machinery in abiotic stress tolerance in crop plants. Plant Physiol. Biochem. 48: 909-930.

Grümberg, B.C., Urcelay, C., Shroeder, M.A., Vargas-Gil, S., and Luna, C.M. 2015. The role of inoculum identity in drought-stress mitigation by arbuscular mycorrhizal fungi in soybean. Biol. Fertil. Soils, 51: 1-10.

Hancock, J.F. 2005. Contributions of domesticated plant studies to our understanding of plant evolution. Ann. Bot. 96:953-63.

Heckman, J.R., and Angle, J.S. 1987. Variation between soybean cultivars in vesiculararbuscular mycorrhiza fungi colonization. Agron. J. 79: 428-430.

Hetrick, B.A.D., G.W.T. Wilson, and T.S. Cox. 1992. Mycorrhizal dependence of modern wheat varieties, landraces, and ancestors. Can. J. Bot. 70: 2032-2040.

Hetrick, B.A.D., G.W.T. Wilson, B.S. Gill, and T.S. Cox. 1995. Chromosomal location of mycorrhizal responsive genes in wheat. Can. J. Bot. 73: 891-897.

Hodges, D.M., DeLong, J.M., Forne, C.F., and Prange, R.K. 1999. Improving the thiobarbituric acid-reactive-substances assay for estimating lipid peroxidation in plant tissues containing anthocyanin and other interfering compounds. Planta, 207: 604-611.

Jackson, L.E. 1995. Root architecture in cultivated and wild lettuce (Lactuca spp.). Plant Cell Environ. 18: 885-894.

Janos, D.P. 2007. Plant responsiveness to mycorrhizas differs from dependence upon mycorrhizas. Mycorrhiza, vol.17. pp. 17-75.

Jugran, A.K.A., Bahukhandi, P., Dhyani, Bhatt, I.D., Rawal, R.S., Nandi, S.K., Palni, L.M.S. 2015. The effect of inoculation with mycorrhiza: AM on growth, phenolics, tannins, phenolic composition and antioxidant activity in Valeriana jatamansi Jones. Journal of Soil Science and Plant Nutrition, 15: 1036-1049.

Kapulnik, Y., Kushnir, U. 1991. Growth dependency of wild, primitive and modern cultivated wheat lines on vesicular-arbuscular mycorrhiza fungi. Euphytica, 56: 27-36.

Khalil, S., Loynachan, T.E., and Tabatabai, M.A. 1994. Mycorrhizal dependency and nutrient uptake by improved and unimproved corn and soybean cultivars. Agron. J. 86: 949-958.

Khalil, S., Loynachan, T.E., and Tabatabai, M.A. 1999. Plant determinants of mycorrhizal dependency in soybean. Agron. J. 91: 135-141.

Lehmann, A., Barto, E.K., Powell, J.R., and Rillig, M. C. 2012. Mycorrhizal responsiveness trends in annual crop plants and their wild relatives - a meta-analysis on studies from 1981 to 2010. Plant and Soil, 355: 231-250. 

activities in lavender plants colonized by native drought-tolerant or drought-sensitive Glomus species.

420

421

422

423

424

425

426

427

428

429

430

431

432

433

434

435

436

437

438

439

440

441

442

443

444

445

446

447

448

449

450

451

452

453

454

455

456

457
Microbial Ecology, 54: 543.

McGonigle, T.P., Miller, M.H., Evans, D.G., Fairchild, G.L., and Swan, J.A. 1990. A method which gives an objective measure of colonization of roots by vesicular-arbuscular mycorrhizal fungi. New Phytol. 115: 495-501.

Mohammadi, P.P., Moieni, A., Hiraga, S., and Komatsu, S. 2012. Organ specific proteomic analysis of drought-stressed soybean seedlings. J. Proteomics, 75: 1906-1923.

Nath, M., Bhatt, D., Prasad, R., Gill, S.S., Anjum, N.A., and Tuteja, T 2016. Reactive Oxygen Species Generation-Scavenging and Signaling during Plant-Arbuscular Mycorrhizal and Piriformospora indica Interaction under Stress Condition. Front. Plant Sci. vol.7.

Ozden, M., Demirel, U., and Kahraman, A. 2009. Effects of proline on antioxidant system in leaves of grapevine (Vitis vinifera L.) exposed to oxidative stress by H2O2. Scientia Horticulturae, 119: $163-168$.

Park, H.J., Floss, D.S., Levesque-Tremblay, V., Bravo, A., and Harrison, M.J. 2015. Hyphal branching during arbuscule development requires RAM1. J. Plant Physiol. pp.01155.

Perez-Brandán, C., Arzeno, J.L., Huidobro, J., Grümberg, B., Conforto, C., Hilton, S., and Vargas-Gil, S. 2012. Long-term effect of tillage systems on soil microbiological, chemical and physical parameters and the incidence of charcoal rot by Macrophomina phaseolina (Tassi) Goid in soybean. Crop. Prot. 40: 73-82.

Pérez-Jaramillo, J.E., Mendes, R., and Raaijmakers, J.M. 2016. Impact of plant domestication on rhizosphere microbiome assembly and functions. Plant Molec. Boil. 90: 635-644.

Phillips, J.M., and Hayman, D.S. 1970. Improved procedure of clearing roots and staining parasitic and vesicular-arbuscular mycorrhizal fungi for rapid assessment of infection. Trans. Br. Mycol. Soc. 55: 159-161.

Plenchette, C., Fortin, J.A., and Furlan, V. 1983. Growth responses of severalplant species to mycorrhizae in a soil of moderate P-fertility. I Mycorrhizal dependency under field conditions. Plant Soil, 70:199-209.

Porcel, R., and Ruiz-Lozano, J.M. 2004. Arbuscular mycorrhizal influence on leaf water potential, solute accumulation, and oxidative stress in soybean plants subjected to drought-stress. J. Exp. Bot. 55: 1743-1750.

Rapparini, F., and Peñuelas, J. 2014. Mycorrhizal fungi to alleviate drought-stress on plant growth. In Use of Microbes for the Alleviation of Soil Stresses. Springer, New York, 1: 21-42.

Ruiz-Lozano, J.M. 2003. Arbuscular mycorrhizal symbiosis and alleviation of osmotic stress: new perspectives for molecular studies. Mycorrhiza, 13: 309-317.

Ruiz-Lozano, J.M., Azcón, R., Gomez, M. 1995. Effects of arbuscular-mycorrhizal glomus species on drought tolerance: physiological and nutritional plant responses. 61: 456-460.

Saia, S., Amato, G., Frenda, A.S, Giambalvo, D., and Ruisi, P. 2014. Influence of arbuscular mycorrhizae on biomass production and nitrogen fixation of berseem clover plants subjected to water stress. PLoS ONE. vol. 9. 
Salloum, M.S., Guzzo, M.C., Velazquez, M.S., Sagadin, M.B., and Luna, C.M. 2016. Variability in colonization of arbuscular mycorrhizal fungi and its effect on mycorrhizal dependency of improved and unimproved soybean cultivars. Can. J. Microbiol. 62: 1034-1040.

Shukla, A., Kumar, A., Jha, A., Salunkhe, O., and Vyas, D. 2013. Soil moisture levels affect mycorrhization during early stages of development of agroforestry plants. Biol. Fertil. Soils, 49: 545-554.

Singh, A.K., Hamel, C., DePauw, R.M., and Knox, R.E. 2012. Genetic variability in arbuscular mycorrhizal fungi compatibility supports the selection of durum wheat genotypes for enhancing soil ecological services and cropping systems in Canada. Can. J. Microbiol. 58: 293-302.

Smith, S.E, and Smith, F.A. 2011. Roles of arbuscular mycorrhizas in plant nutrition and growth: new paradigms from cellular to ecosystem scales. Annu. Rev.Plant. Biol. 63: 227-250.

Smith, S.E., and Read, D.J. 2008. Mycorrhizal Symbiosis. Academic Press, Inc., San Diego, CA.

Tawaraya, K. 2003. Arbuscular mycorrhizal dependency of different plant species and cultivars. Soil Sci. Plant Nutr. 49: 655-668.

Wu, Q.S., and Xia, R.X. 2006. Arbuscular mycorrhizal fungi influence growth, osmotic adjustment and photosynthesis of citrus under well-watered and water stress conditions. J. Plant Physiol. $163: 417-425$

Wu, H.H., Zou, Y.N., Rahman, M.M., Ni, Q.D., and Wu, Q.S. 2017. Mycorrhizas alter sucrose and proline metabolism in trifoliate orange exposed to drought stress. Scientific Reports. Vol.7.

Xing, X., Koch, A.M., Jones, A.M.P., Ragone, D., Murch, S., and Hart, M.M. 2012. Mutualism breakdown in breadfruit domestication. Proc. R. Soc. Lond. B Biol. Sci. No. 279: 1122-1130.

Zhang, Y., Zhong, C.L., Chen, Y., Chen, Z., Jiang, Q.B., Wu, C., and Pinyopusarerk, K. 2010. Improving drought tolerance of Casuarina equisetifolia seedlings by arbuscular mycorrhizas under glasshouse conditions. New For, 40: 261-270.

Zhu, X., Song, F., and Liu, S. 2011. Arbuscular mycorrhiza impacts on drought stress of maize plants by lipid peroxidation, proline content and activity of antioxidant system. J. Food Agric. Environ. 9: 583-587.

Zhu, Y.G., Smith, S.E., Barritt, A.R., and Smith, F.A. 2001. Phosphorus (P) efficiencies and mycorrhizal responsiveness of old and modern wheat cultivars. Plant and Soil, 237: 249-255.

\section{Figure captions}

Fig.1: Effects of inoculation with arbuscular mycorrhizal fungi on root dry mass, shoot dry mass and leaf area evaluated as mycorrhizal dependency (MD) in unimproved (UI-1 to UI-4) and improved (I-1 to I-4) soybean genotypes after 20 days of treatment, under well water conditions. Values are means $\pm \mathrm{SD}$ ( $n=10$ plants). The same letter within each column indicates no significant difference among treatments according to least significant difference tests at $p<0.05$

Fig.2: Effects of inoculation with arbuscular mycorrhizal fungi on nutrient content in leaves of soybean genotypes evaluated as mycorrhizal dependency (MD): A) NO3 content ;B) P04 content, C) SO4 content, after 20 days of treatment under well water conditions. UI: unimproved soybean genotypes (UI-1 to UI-4); I: improved soybean genotypes (I-1 to I-4). Values are means $\pm \mathrm{SD}$ ( $n=10$ plants). The same 
497 letter within each column indicates no significant difference among treatments according to least

498

499

500

501

502

503

504

505

506

507

508

509

510

511

512

513

514

515

516

517

518

519

520

521

522

523 significant difference tests at $p<0.05$.

Fig.3: Effects of inoculation with arbuscular mycorrhizal fungi on A) Shoot dry mass and B) Leaf area, evaluated as mycorrhizal dependency (MD) in improved (I-1 and I-2) and unimproved (UI-3 and UI-4) soybean genotypes under well water and drought (30\% field capacity) conditions. Values are means \pm SD ( $n=10$ plants). The same letter within each column indicates no significant difference among treatments according to least significant difference tests at $p<0.05$.

Fig.4: Effects of inoculation with arbuscular mycorrhizal fungi on chlorophyll content evaluated as mycorrhizal dependency (MD) in improved (I-1 and I-2) and unimproved (UI-3 and UI-4) soybean genotypes under well water and drought (30\% field capacity) conditions. Values are means \pm SD $(n=10$ plants). The same letter within each column indicates no significant difference among treatments according to least significant difference tests at $p<0.05$.

Fig.5: Effects of inoculation with arbuscular mycorrhizal fungi on malondialdehyde (MDA) content evaluated as mycorrhizal dependency (MD) in improved (I-1 and I-2) and unimproved (UI-3 and UI-4) soybean genotypes under well water and drought (30\% field capacity) conditions. Values are means $\pm \mathrm{SD}(n=10$ plants). The same letter within each column indicates no significant difference among treatments according to least significant difference tests at $p<0.05$.

Fig.6: Effects of inoculation with arbuscular mycorrhizal fungi on antioxidant activity of ferric reducing ability of plasma (FRAP) content evaluated as mycorrhizal dependency (MD) in improved (I-1 and I-2) and unimproved (UI-3 and UI-4) soybean genotypes under well water and drought (30\% field capacity) conditions. Values are means $\pm \mathrm{SD}$ ( $n=10$ plants). The same letter within each column indicates no significant difference among treatments according to least significant difference tests at $p<0.05$.

Fig.7: Effects of inoculation with arbuscular mycorrhizal fungi on proline content evaluated as mycorrhizal dependency (MD) in improved (I-1 and I-2) and unimproved (UI-3 and UI-4) soybean genotypes under well water and drought ( $30 \%$ field capacity) conditions. Values are means \pm SD $(n=10$ plants). The same letter within each column indicates no significant difference among treatments according to least significant difference tests at $p<0.05$. 
Table 1. Variability of mycorrhizal colonization and structures in unimproved (UI, 1-4) and improved (I, 1-4) soybean genotypes, after 20 days of treatment with AMF under well-water conditions.

\begin{tabular}{|c|c|c|c|c|}
\hline $\begin{array}{l}\text { Soybean } \\
\text { genotypes }\end{array}$ & $\begin{array}{l}\text { Total }(\%) \\
\text { Root } \\
\text { Colonization }\end{array}$ & $\begin{array}{l}\text { Root } \\
\text { colonization } \\
\text { (\%) by hyphae }\end{array}$ & $\begin{array}{l}\text { Root } \\
\text { colonization } \\
(\%) \text { by vesicles }\end{array}$ & $\begin{array}{l}\text { Root colonization } \\
\text { (\%) by arbuscules }\end{array}$ \\
\hline UI-1 & $40 a$ & $8 a$ & $2 a$ & $30 a$ \\
\hline UI-2 & $42 a$ & $9 a$ & $1 a$ & $32 a$ \\
\hline UI-3 & $38 a$ & $10 a$ & $3 a$ & $25 b$ \\
\hline UI-4 & $41 a$ & $5 b$ & $1 a$ & $34 a$ \\
\hline I-1 & $25 c$ & $8 a$ & $5 b$ & $12 d$ \\
\hline $\mathrm{I}-2$ & $32 b$ & $8 a$ & $2 a$ & $22 b$ \\
\hline $\mathrm{I}-3$ & $28 b$ & $4 b$ & $4 b$ & $20 c$ \\
\hline $\mathrm{I}-4$ & $30 b$ & $6 b$ & $7 b$ & $18 c$ \\
\hline
\end{tabular}

Values are means \pm SD ( $n=10$ plants). The same letter within each column indicates no significant difference among treatments according to least significant difference tests at $p<0.05$. 
Table 2. Arbuscular mycorrhizal fungus colonization of roots of improved and unimproved soybean genotypes (improved genotypes: I-1 and I-2: unimproved genotypes: UI-3 and UI-4) after 20 days of drought stress. Watering conditions (W), drought stress conditions (DS)

\begin{tabular}{|c|c|c|c|c|}
\hline Genotypes & $\begin{array}{l}\text { Total root } \\
\text { colonization (\%) }\end{array}$ & $\begin{array}{l}\text { Root colonization } \\
\text { by hyphae }(\%)\end{array}$ & $\begin{array}{l}\text { Root colonization by } \\
\text { coiled hyphae }(\%)\end{array}$ & $\begin{array}{l}\text { Root colonization } \\
\text { by arbuscules }(\%)\end{array}$ \\
\hline & W DS & DS & DS & DS \\
\hline UI-3 & $37 c \quad 32 g$ & $12 b \quad 10 b$ & $\begin{array}{ll}3 b & 2 b\end{array}$ & $22 c \quad 19 c$ \\
\hline UI-4 & $41 d \quad 34 g$ & $16 a \quad 14 a$ & $0 c \quad 0 c$ & $25 d \quad 20 c$ \\
\hline $\mathrm{I}-1$ & $25 a \quad 20 e$ & $15 a \quad 13 a$ & $10 a$ & $4 e$ \\
\hline $\mathrm{I}-2$ & $34 b \quad 28 f$ & $10 b \quad 13 a$ & $8 a$ & $15 b \quad 12 b$ \\
\hline
\end{tabular}

The same letter within each column (treatments) indicates no significant differences among treatments, according to least significant difference tests at $p<0.05$. 


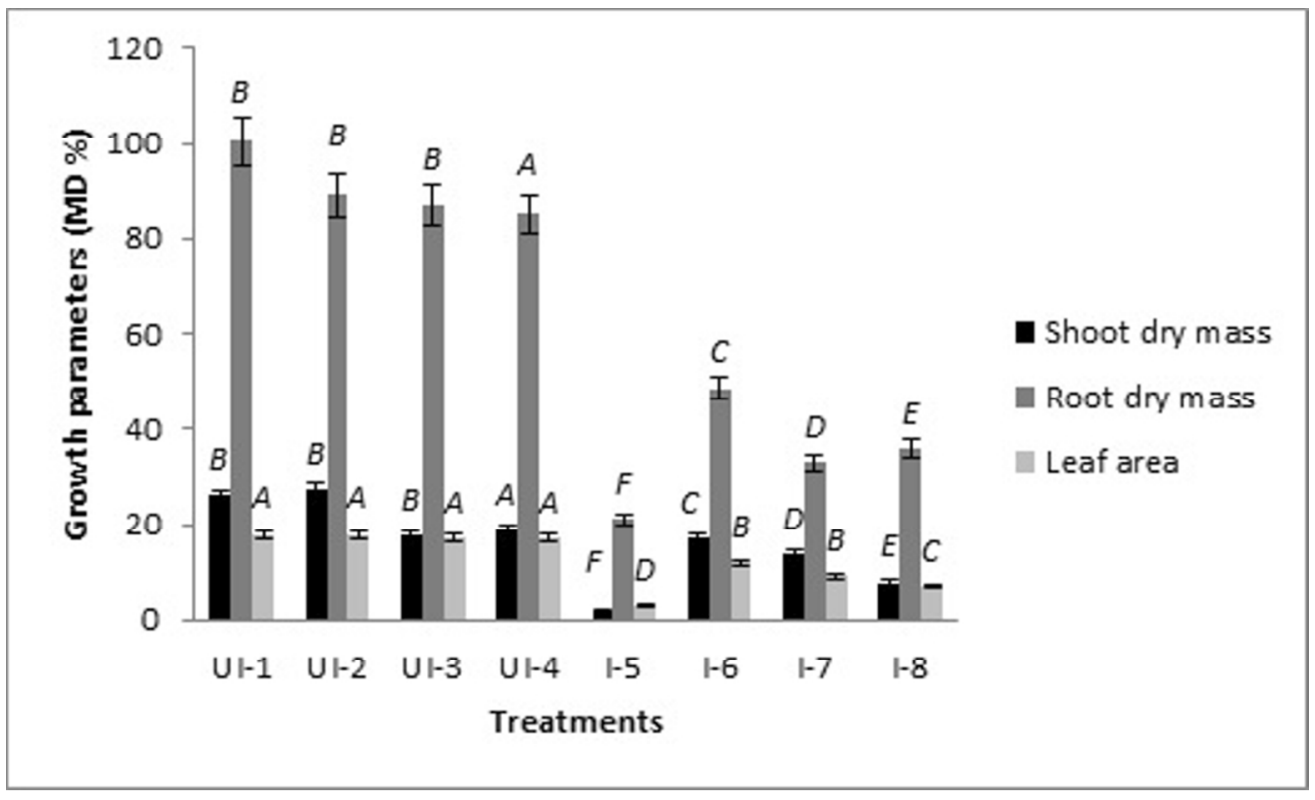

Fig. 1.

$84 \times 50 \mathrm{~mm}(300 \times 300$ DPI $)$ 


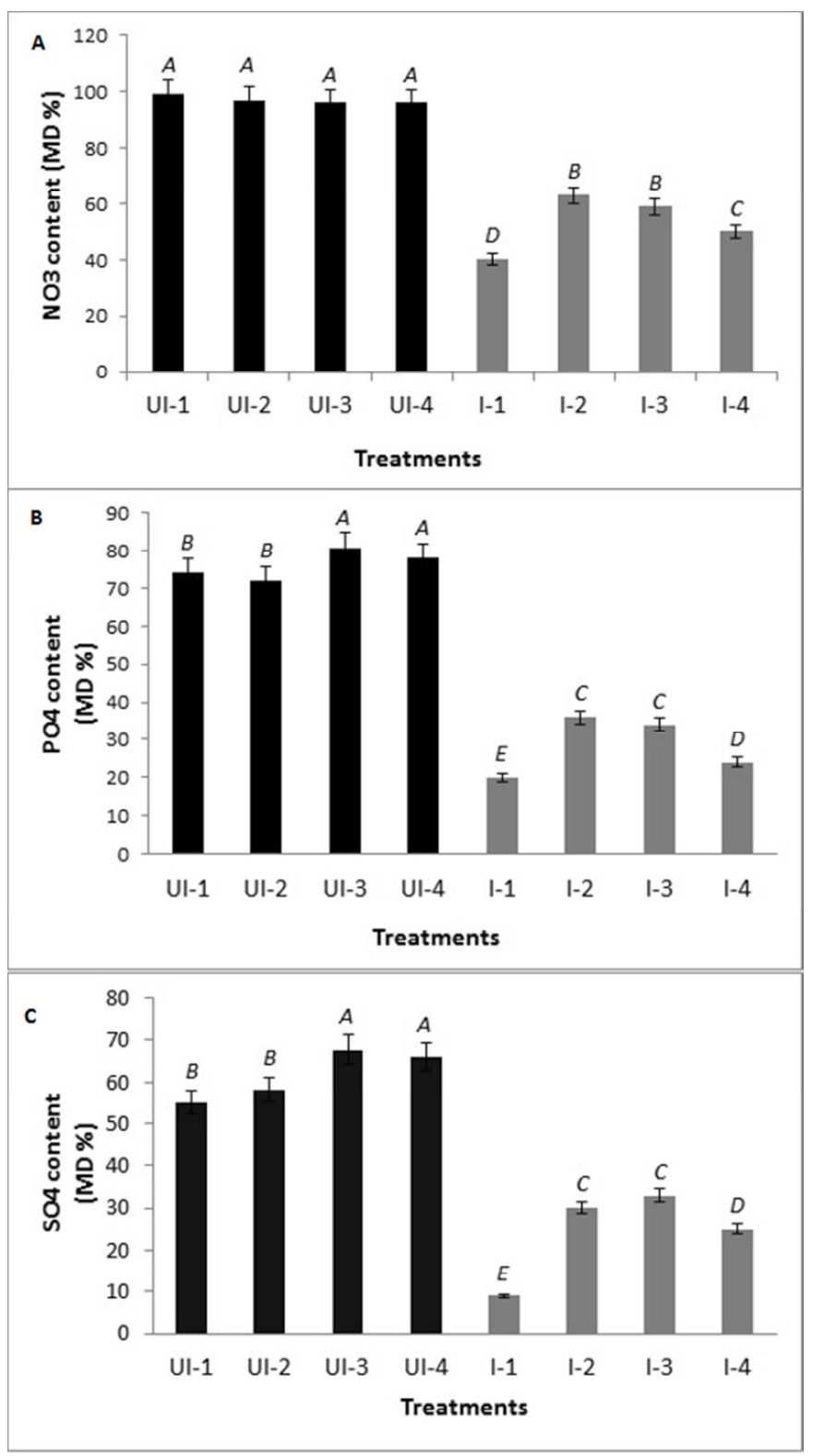

Fig. 2.

$46 \times 84 \mathrm{~mm}(300 \times 300 \mathrm{DPI})$ 


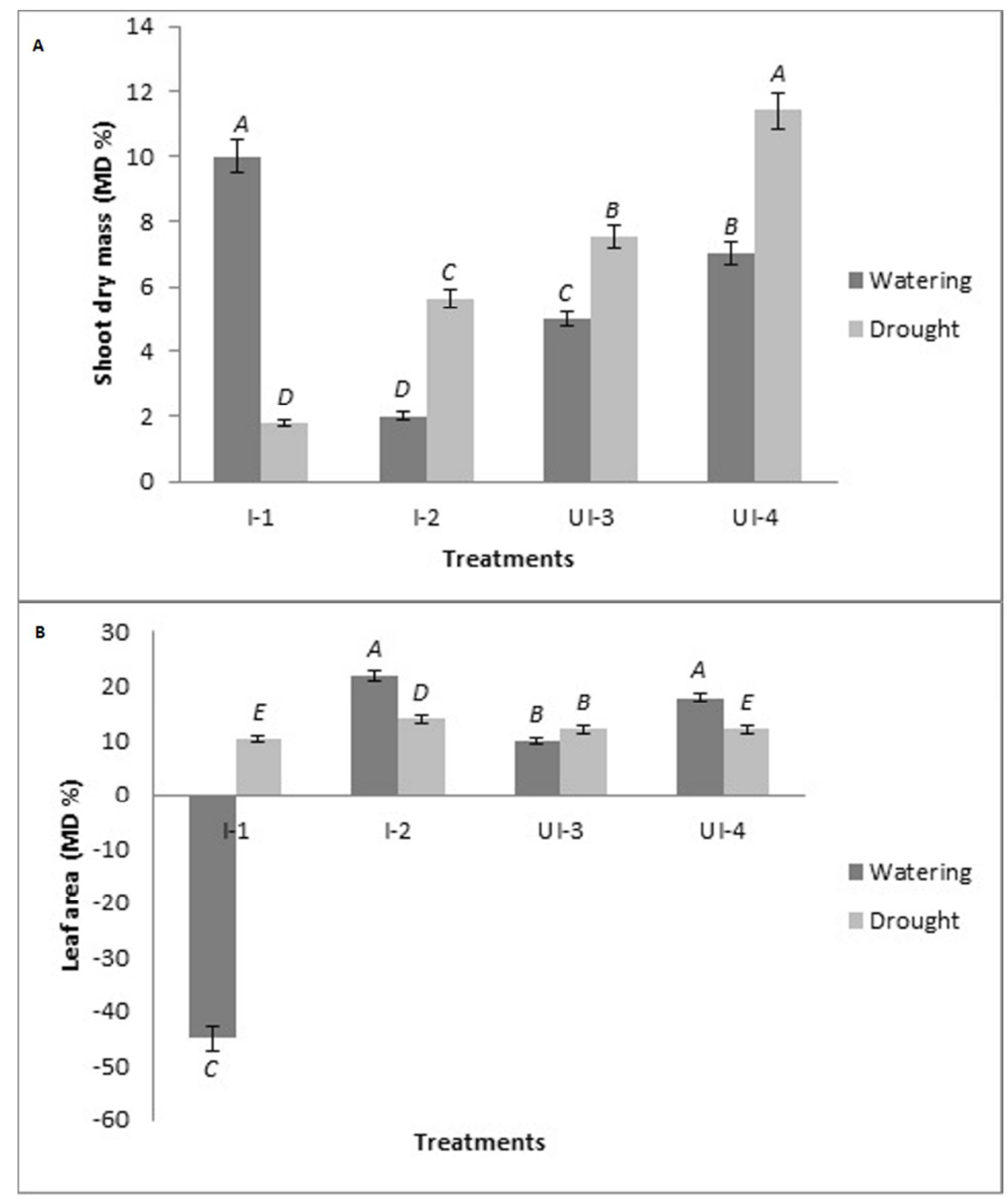

Fig. 3.

$70 \times 84 \mathrm{~mm}(300 \times 300$ DPI $)$ 


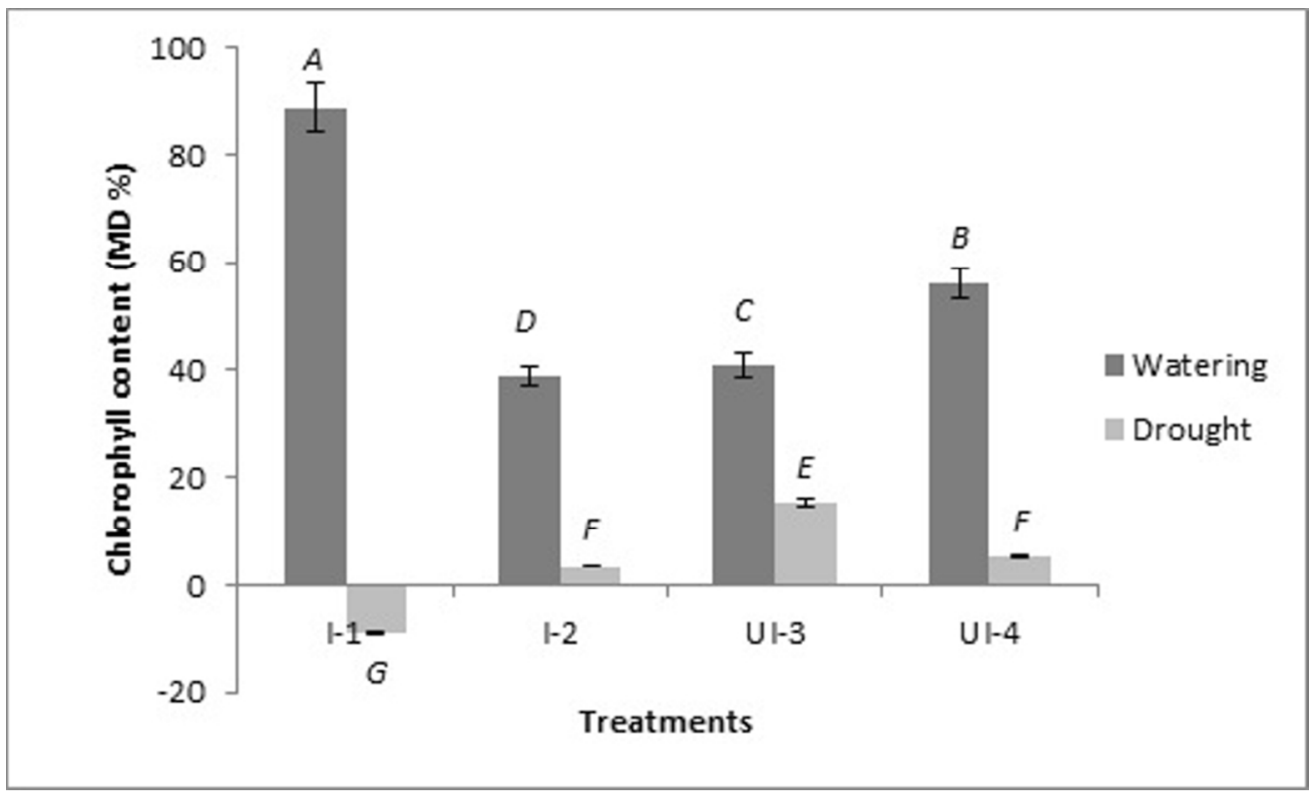

Fig. 4.

$84 \times 50 \mathrm{~mm}(300 \times 300 \mathrm{DPI})$ 


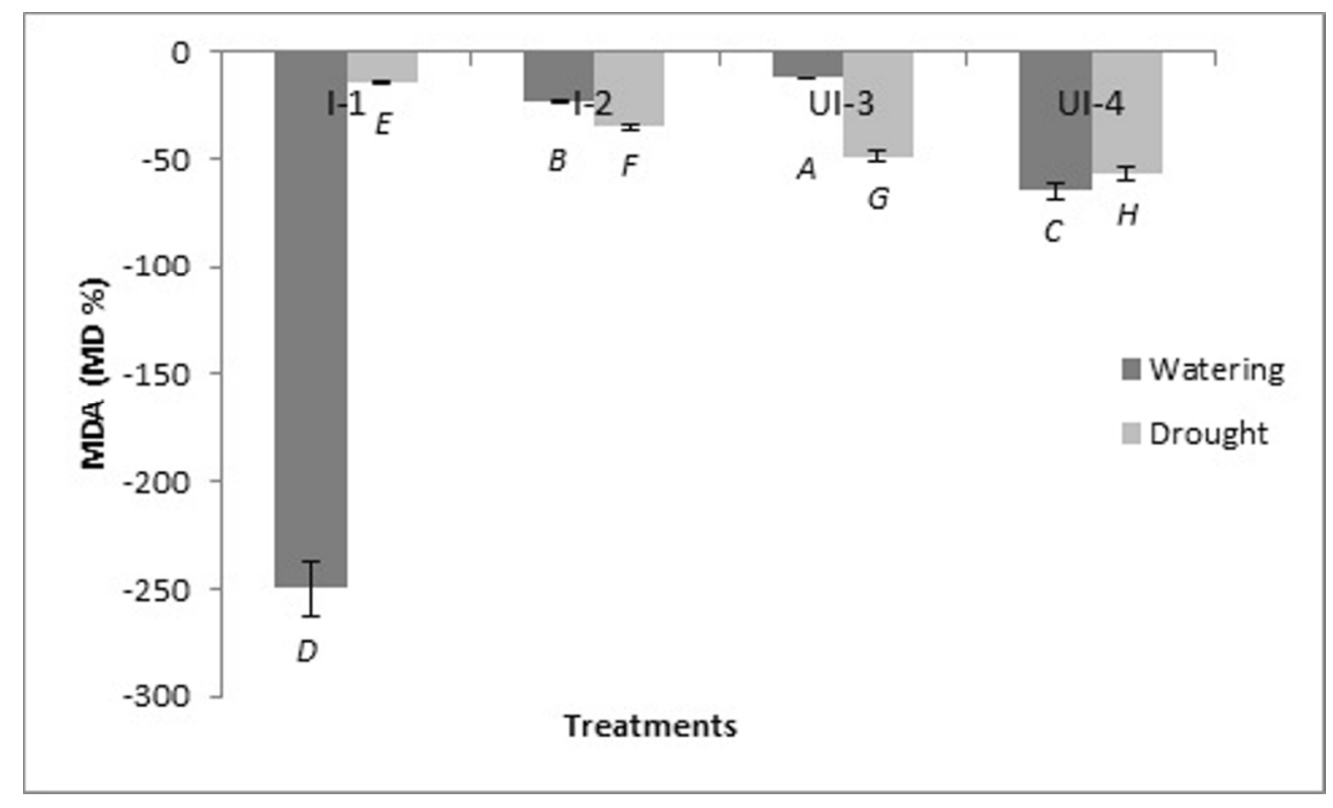

Fig. 5.

$84 \times 50 \mathrm{~mm}(300 \times 300$ DPI $)$ 


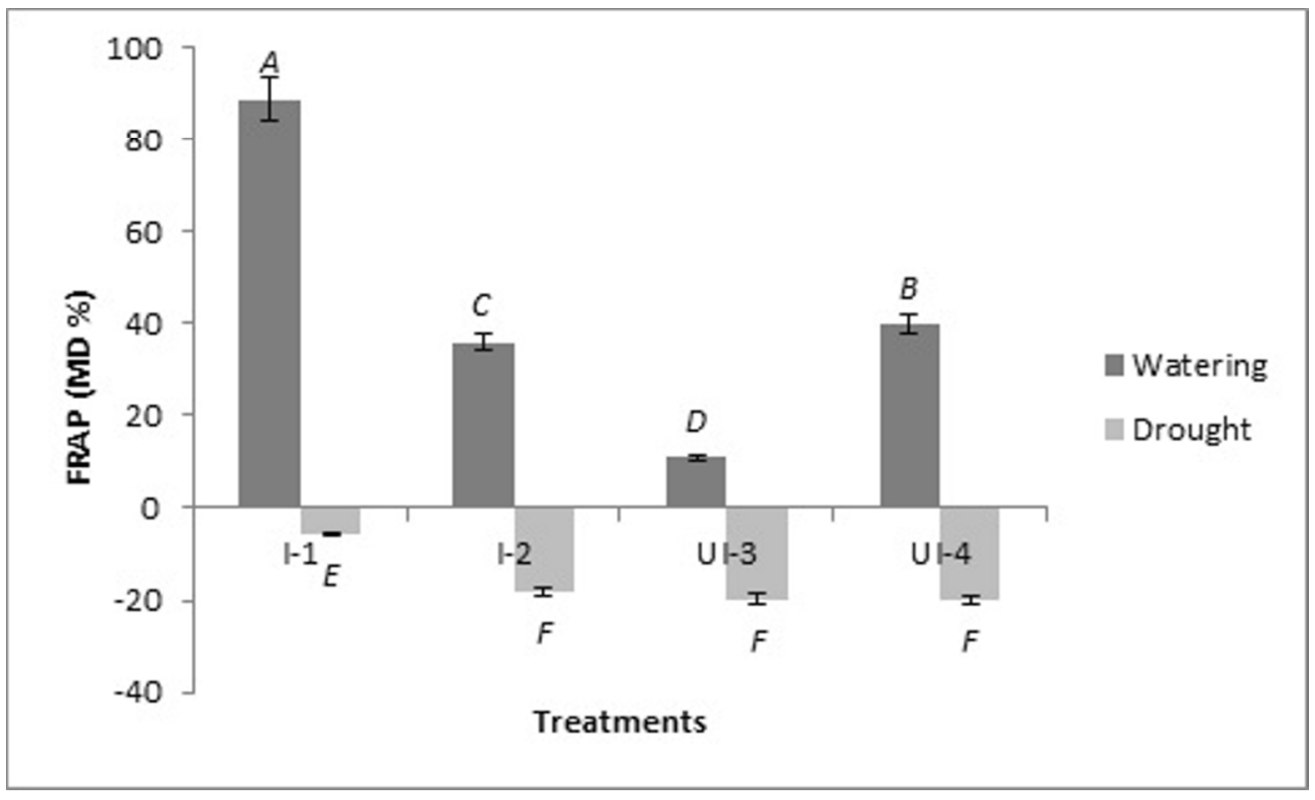

Fig. 6.

$84 \times 50 \mathrm{~mm}(300 \times 300 \mathrm{DPI})$ 


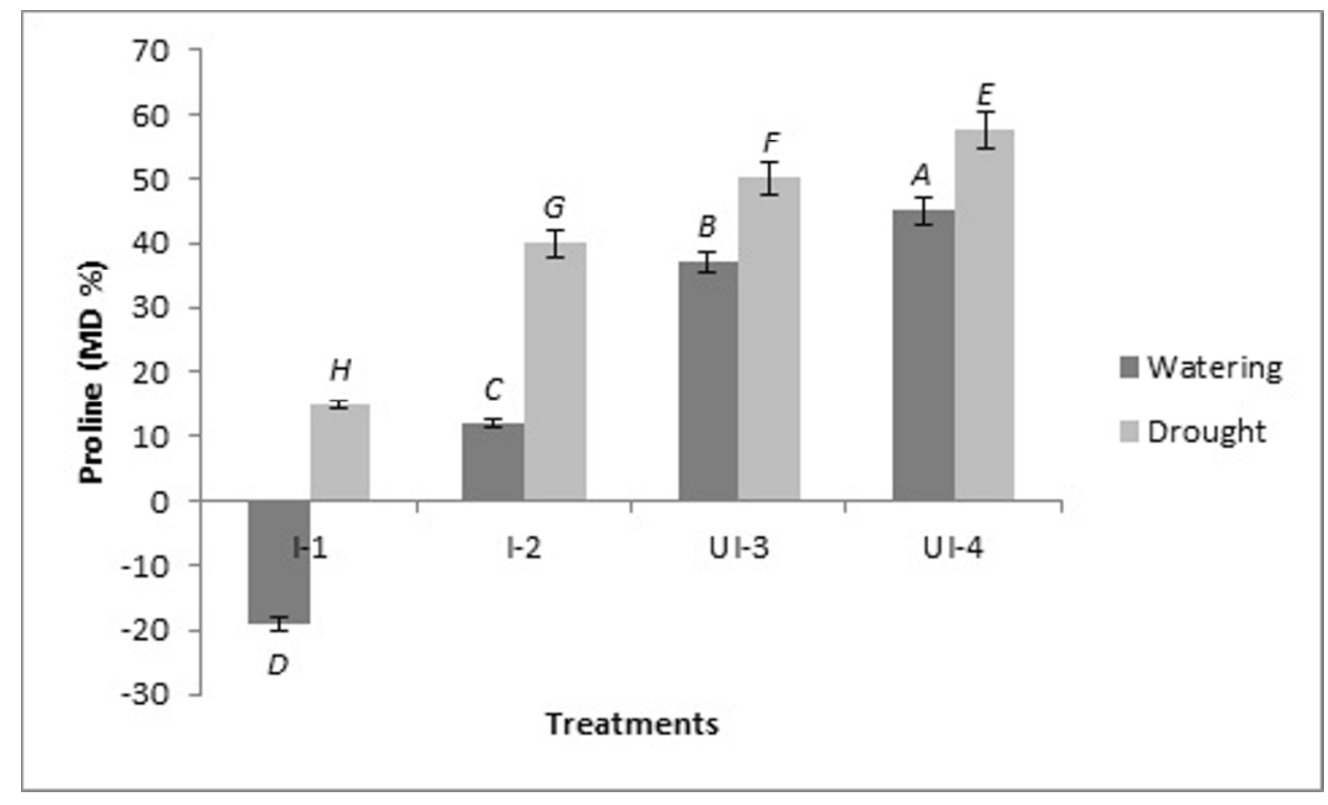

Fig. 7.

$84 \times 50 \mathrm{~mm}(300 \times 300$ DPI $)$ 